\title{
Atmospheric Kármán Vortex Shedding from Jeju Island, East China Sea: A Numerical Study*
}

\author{
JUNSHI ITO ${ }^{+}$AND HIROSHI NIINO \\ Atmosphere and Ocean Research Institute, University of Tokyo, Kashiwa, Chiba, Japan
}

(Manuscript received 8 December 2014, in final form 7 October 2015)

\begin{abstract}
A mesoscale atmospheric numerical model is used to simulate two cases of Kármán vortex shedding in the lee of Jeju Island, South Korea, in the winter of 2013. Observed cloud patterns associated with the Kármán vortex shedding are successfully reproduced. When the winter monsoon flows out from the Eurasian continent, a convective mixed layer develops through the supply of heat and moisture from the relatively warm Yellow Sea and encounters Jeju Island and dynamical conditions favorable for the formation of lee vortices are realized. Vortices that form behind the island induce updrafts to trigger cloud formation at the top of the convective boundary layer. A sensitivity experiment in which surface drag on the island is eliminated demonstrates that the formation mechanism of the atmospheric Kármán vortex shedding is different from that behind a bluff body in classical fluid mechanics.
\end{abstract}

\section{Introduction}

It is well known in fluid mechanics that Kármán vortex shedding occurs when a uniform flow encounters a bluff body (e.g., Mallock 1907; von Kármán and Rubach 1912). A similar vortex shedding occurs when an atmospheric flow strikes an isolated mountain, and can be observed by satellite when the vortices are accompanied by clouds or disturb a nearly homogeneous layer of stratocumulus. Such a phenomenon is perhaps one of the most attractive images of pattern formation in nature.

Earlier studies on atmospheric Kármán vortex shedding suggested its similarity to that observed in laboratory experiments without density stratification (e.g., Tsuchiya 1969; Jensen and Agee 1978; Ruscher and Deardorff 1982), where the vorticity originates from

\footnotetext{
* Supplemental information related to this paper is available at the Journals Online website: http://dx.doi.org/10.1175/MWR-D14-00406.s1.

${ }^{+}$Current affiliation: Meteorological Research Institute, Japan Meteorological Agency, Tsukuba, Ibaraki, Japan.
}

Corresponding author address: Junshi Ito, Atmosphere and Ocean Research Institute, University of Tokyo, 5-1-5 Kashiwanoha, Kashiwa, Chiba 277-8564, Japan.

E-mail: junshi@aori.u-tokyo.ac.jp viscous boundary layers on a bluff obstacle. Subsequent research, however, has pointed out the importance of density stratification in atmospheric Kármán vortex shedding, as reviewed in Young and Zawislak (2006). Laboratory experiments (Etling 1989), theoretical work (Schär and Smith 1993), and numerical simulation (Epifanio and Rotunno 2005) have suggested that viscous boundary layers are not essential for the atmospheric case. As specific to the stratified fluids, lee vortices are formed due to the baroclinicity of flows going over the mountain (e.g., Smolarkiewicz and Rotunno 1989) or gravity wave breaking behind the mountain (e.g., Kang et al. 1998) that causes a deceleration of the flow and a resulting horizontal shear instability (e.g., Schär and Durran 1997). Numerical simulations (Rotunno and Smolarkiewicz 1991; Schär and Durran 1997; Epifanio and Rotunno 2005) have demonstrated that both of these distinct physical processes are present. Heinze et al. (2012) have performed a large-eddy simulation (LES) with high horizontal resolution $(50 \mathrm{~m})$ to investigate the morphology of the vortices that form behind a mountain.

These idealized numerical studies have focused on the mechanism of atmospheric Kármán vortex shedding and have unveiled some of its important aspects. However, there have been few simulations of Kármán vortex shedding in the real atmosphere and most of them have focused on Madeira Island in the northeast Atlantic ( $\mathrm{Li}$ et al. 2008; Couvelard et al. 2012; Caldeira and Tomé 

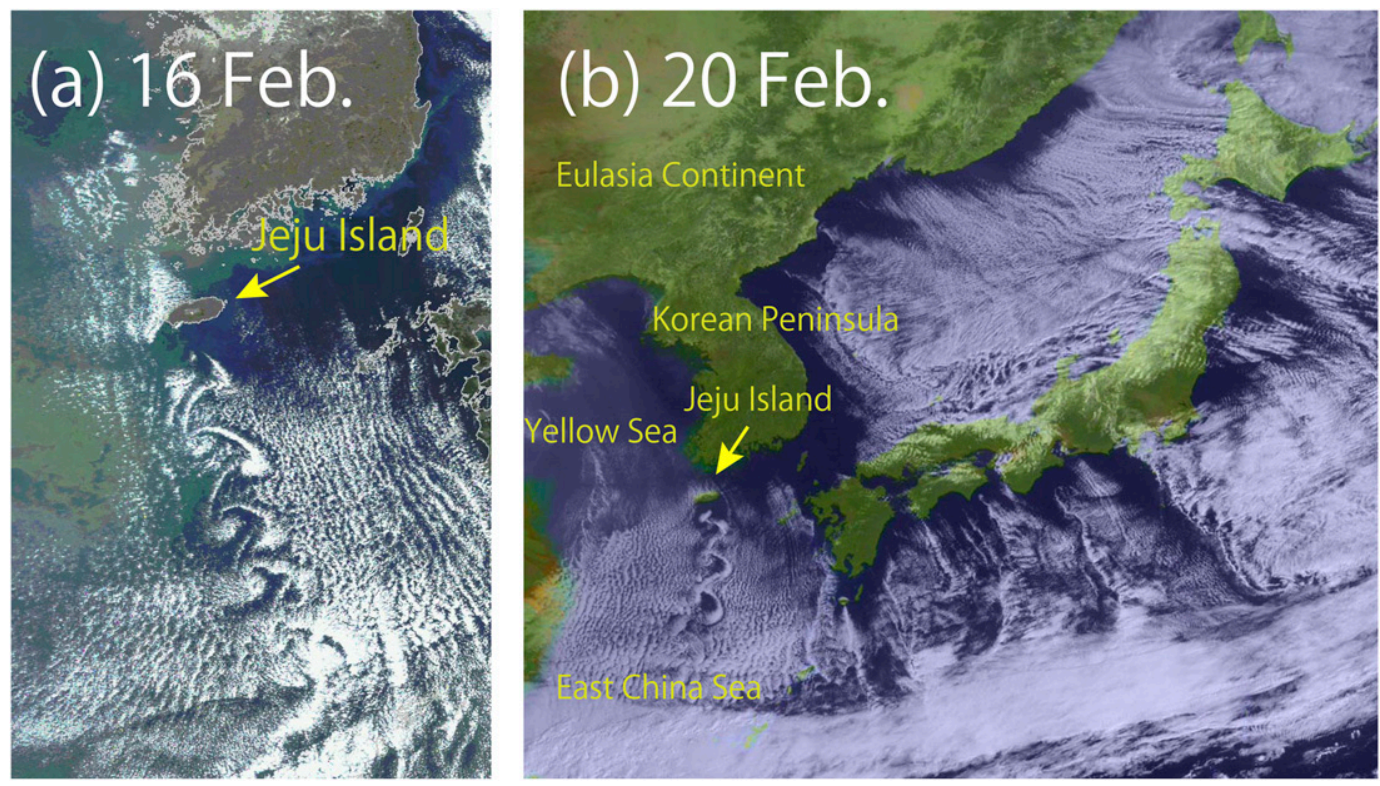

FIG. 1. (a) A MODIS image of corrected cloud reflectance from the polar orbiter Terra at 0159 UTC 16 Feb 2013 (courtesy of JAXA/Tokai University) and (b) a visible image from the geostationary satellite MTSAT-2 at 0100 UTC $20 \mathrm{Feb} 2013$ (courtesy of JMA/Kochi University). Both images show Kármán vortex shedding behind Jeju Island; a higher-resolution image from the polar orbiter was not available for $20 \mathrm{Feb} 2013$.

2013; Nunalee and Basu 2014). Nunalee and Basu (2014) used a numerical simulation model with a horizontal resolution of $2 \mathrm{~km}$, and obtained a cloud pattern that resembles a satellite image of cellular stratocumulus, where clouds covering the whole region are disturbed by Kármán vortex shedding [see Fig. 3 in Nunalee and Basu (2014)]. However, they did not examine the detailed mechanism of the cloud formation.

The region in the wake of Jeju Island in the East China Sea is also known for the frequent occurrence of atmospheric Kármán vortex shedding, and there have been observational studies of the vortex shedding in this region (Tsuchiya 1969; Jensen and Agee 1978; Ruscher and Deardorff 1982; Chung and Kim 2008). The cases studied in this paper occurred on 16 and 20 February 2013 when satellite images clearly capture Kármán vortex shedding behind Jeju Island (Fig. 1). While Kármán vortices in the majority of other recent studies [e.g., Nunalee and Basu (2014) for Madeira Island; Muller et al. (2015) for Grover Beach, California; and Ágústsson and Ólafsson (2014) for the west of Reykjavík, Iceland] occur in a region filled with stratocumulus clouds, and are accompanied with a cloudfree region at their centers, those in this study are formed in a region with longitudinal cloud streets that have been studied theoretically (Asai 1970) and numerically (e.g., Gryschka et al. 2014) during a cold-air outbreak.

In this paper, a mesoscale nonhydrostatic model including bulk microphysical parameterizations is used to reproduce the observed Kármán vortex shedding behind
Jeju Island. Initial and boundary conditions are given by the mesoscale objective analysis data (MANL) of the Japan Meteorological Agency (JMA). Based on the numerical simulations of the real cases, we investigate the dynamics and environment of Kármán vortex shedding, as in previous studies, as well as the formation of the characteristic cloud by the vortices.

\section{Numerical simulation by a mesoscale model}

The present study employs the JMA nonhydrostatic mesoscale model (NHM; Saito et al. 2006) for numerical simulations. The size of the domain is $802 \mathrm{~km} \times 1202 \mathrm{~km}$ in the horizontal and about $22 \mathrm{~km}$ in the vertical. The region with color shading in Fig. 2 shows the whole computational domain, with Jeju Island located near the center. The horizontal grid interval is $2 \mathrm{~km}$, and the vertical grid interval varies from $40 \mathrm{~m}$ near the surface to about $1 \mathrm{~km}$ near the top of the domain. A three-ice single-moment bulk scheme (Lin et al. 1983) was used for cloud microphysics parameterization, while cumulus parameterization was not used; the boundary layer parameterization employs the Mellor-Yamada-Nakanishi-Niino (MYNN level-2.5; Nakanishi and Niino 2006) scheme; the surface fluxes are parameterized by Beljaars and Holtslag (1991); and shortwave and longwave radiation schemes are summarized in section $4 \mathrm{~h}$ in Saito et al. (2006). These settings are almost the same as those of an operational regional forecast model used by the JMA (Hirahara et al. 2011). 

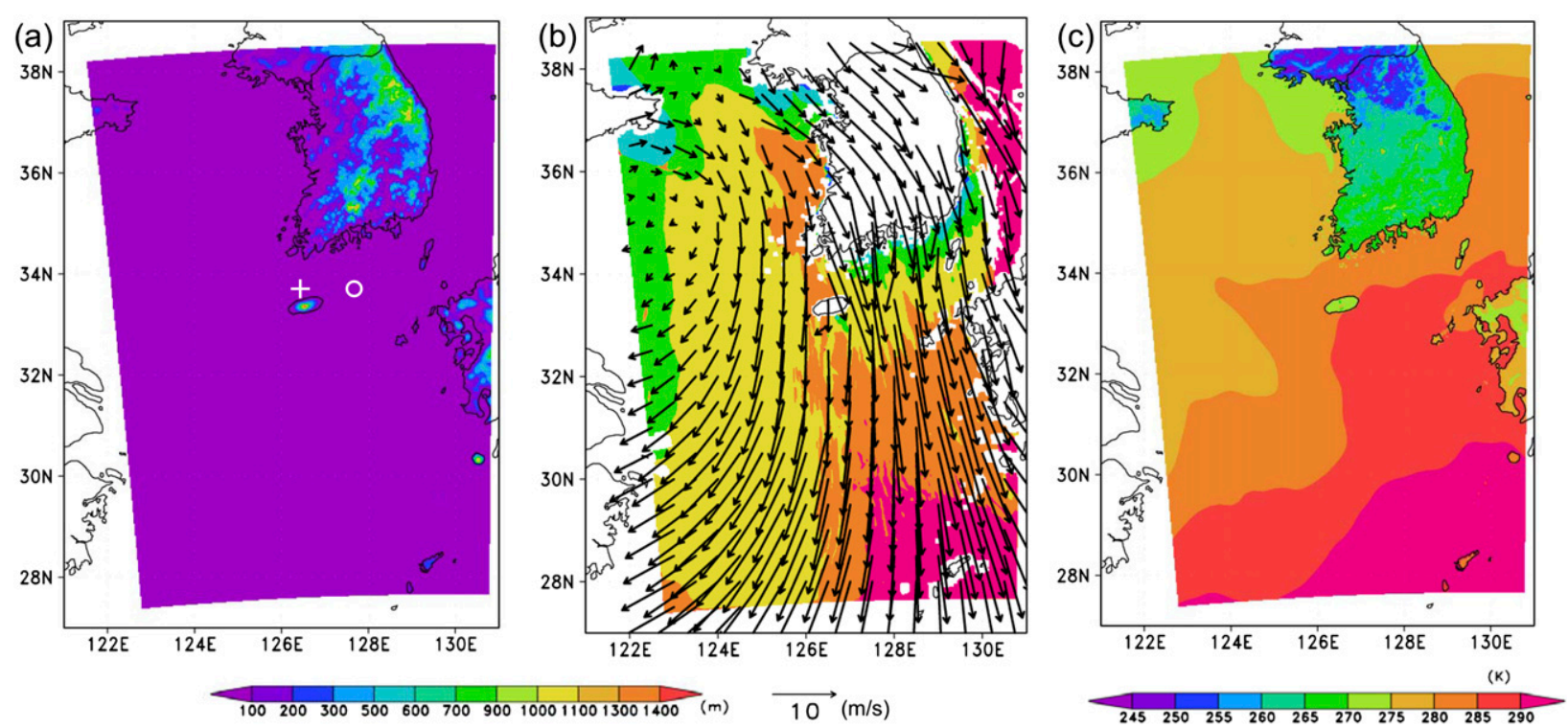

FIG. 2. (a) Height of the topography (bottom layer) of the numerical model, (b) height of the CBL over the sea (shading) and horizontal wind vectors at $z=844 \mathrm{~m}$ of the simulation result, and (c) surface temperature of the analysis data at 0000 UTC 16 Feb 2013 . The white plus and circle in (a) denote the location where the vertical profiles in Fig. 5 are presented.

The numerical model adopts a terrain-following $z^{*}$ coordinate and implements a realistic terrain as presented in Fig. 2a. Jeju Island, indicated by the yellow arrow in Fig. 1, is dominated by Halla Mountain, a volcano of 1950-m height, although the mountain is somewhat smoothed in the model with its height reduced to $1500 \mathrm{~m}$. The long (longitudinal) and short (latitudinal) axes of the island are about 75 and $35 \mathrm{~km}$, respectively.

We performed five 24-h runs initiated at 1200 UTC [2100 Japan standard time (JST)] on each day from 15 to 19 February. For the initial and boundary conditions of the simulation, we used the MANL data with a horizontal resolution of $5 \mathrm{~km}$. Surface temperature (Fig. 2c) is also provided by the JMA. Note that Kármán vortex shedding was not clearly seen in the MANL data nor in our preliminary simulations with a horizontal resolution of $5 \mathrm{~km}$.

\section{Results of the numerical simulation}

The JMA NHM successfully reproduced realistic Kármán vortex shedding accompanied by characteristic clouds in the wake of Jeju Island. Figures $3 \mathrm{a}$ and $3 \mathrm{e}$ show typical cloud patterns at 0000 UTC on both 16 and 20 February. Vortex shedding is more evident in the two animations available in the online supplemental material, which presents time series of those demonstrated in Figs. $3 \mathrm{a}$ and $3 \mathrm{e}$, respectively.

Figure 4 shows a three-dimensional image of simulated cloud water on 16 February, where cloud trains associated with Kármán vortex shedding begin some distance downstream of the island. Clouds that are a part of longitudinal cloud streets are also seen in the upstream of the mountain. Note that the height of these clouds is lower than the top of the mountain.

The size of the vortices and their intervals appear to be comparable with those observed by satellite (Fig. 1). According to the online supplemental animations, the time periods $T$ of the vortex ejection are estimated to be 160 and 140 min on 16 and 20 February, respectively. The corresponding Strouhal numbers $\mathrm{St}=d /(T U)$, the dimensionless frequencies of the vortex ejection, are 0.15 and 0.12 , respectively, where $d \sim 10 \mathrm{~km}$ is the effective horizontal scale of the mountain (c.f. Jensen and Agee 1978) and $U \sim 6.8$ and $10.1 \mathrm{~m} \mathrm{~s}^{-1}$, respectively, are the mean horizontal wind speed over the layer between the top of the mountain and the lowest grid level (Fig. 5b). For Kármán vortex shedding behind a bluff body in an unstratified fluid, $\mathrm{St} \sim 0.2$, while a smaller $\mathrm{St}$ is found in the present study, which is consistent with both previous observations (e.g., Thomson et al. 1977) and numerical simulations (e.g., Heinze et al. 2012) for the atmosphere.

Note that the directions in which the simulated cloud trains extend are also consistent with the observations: the simulated cloud trains on 20 February first extend southeastward, but then bend southwestward at the middle (see online supplemental animation 2), which agrees well with the observations. The times when significant Kármán vortex shedding occurred in the simulation are between 1800 UTC 15 February and 0500 UTC 16 February and between 1800 UTC 19 February and 0800 UTC 20 February, which also agree well with the satellite observations. 

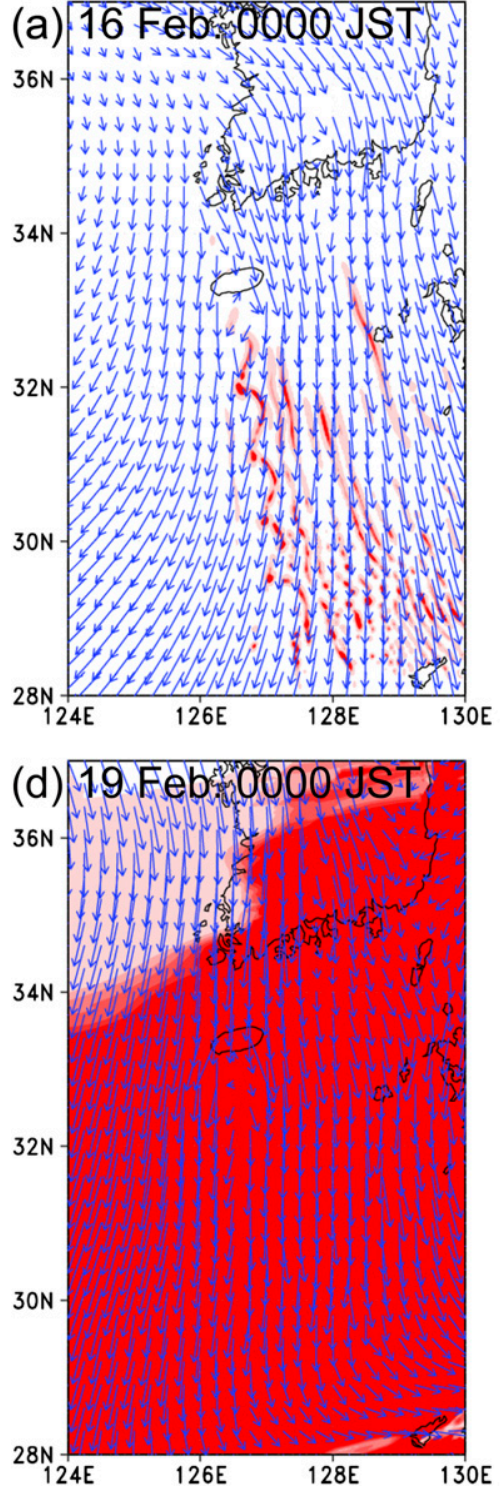
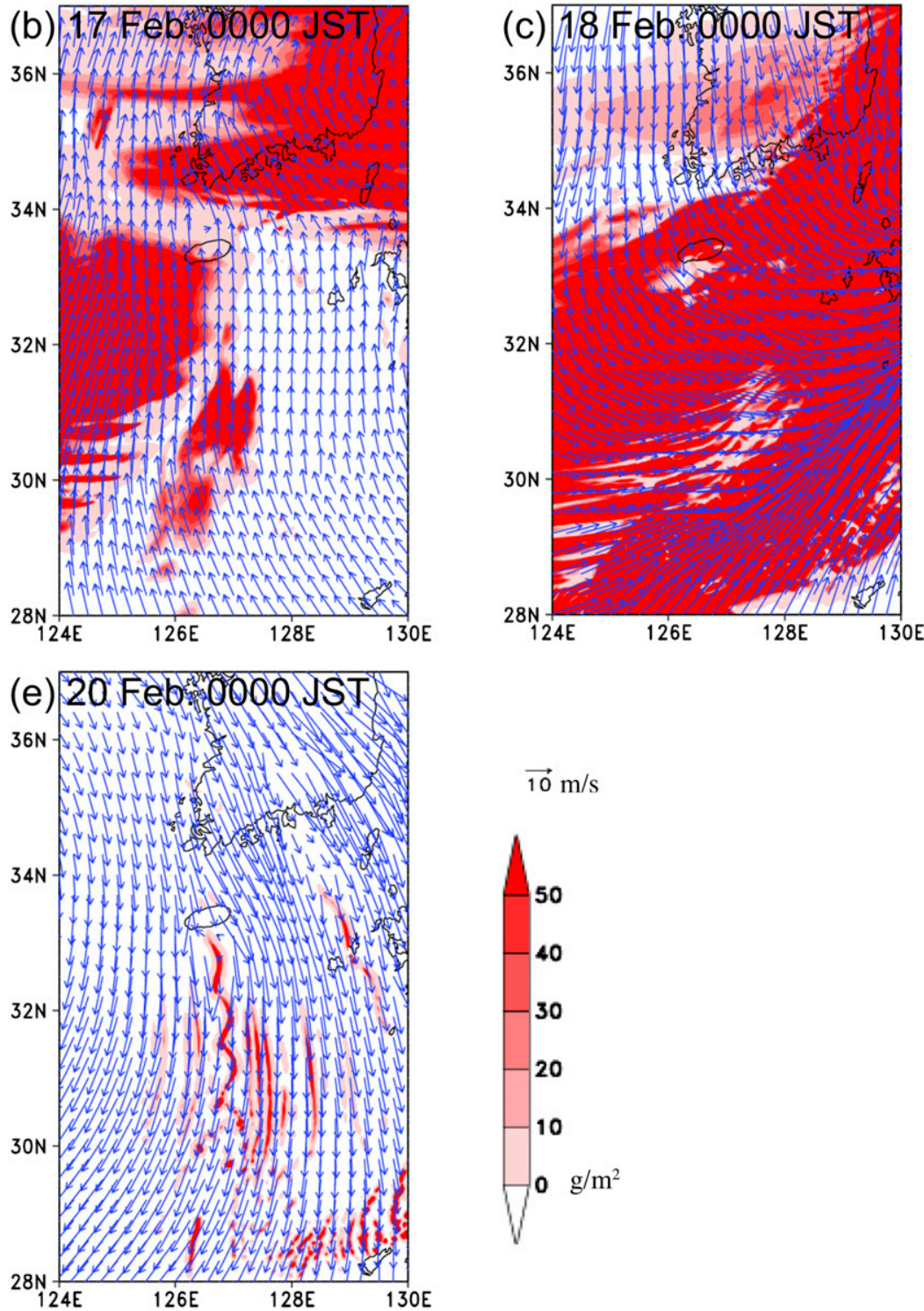

FIG. 3. Vertically integrated cloud water (shading) with horizontal wind vectors at $844 \mathrm{~m}$ above the surface at 0000 UTC on each day for (a)-(e) 16-20 Feb 2013.

The numerical simulation does not reproduce cloud trains associated with Kármán vortex shedding on the other three days $(17,18$, and 19 February) when they were not observed by satellite. Middle or upper-level clouds covered the region on these days (Figs. 3b-d).

\section{Discussion}

\section{a. Environmental conditions}

When the winter monsoon flows out from the Eurasian continent over the ocean, the sea surface is more than $10 \mathrm{~K}$ warmer than the land surface (Fig. 2c), due to the warm Tsushima Current, which is a branch of the Kuroshio. Figure $2 \mathrm{~b}$ shows the height of the convective boundary layer (CBL) $h$ and horizontal winds in the simulation result at 0000 UTC 16 February 2013 when the Kármán vortex shedding is significant. Note that $h$ is determined by the level where the potential temperature gradient $\partial \theta / \partial z>0$ and $\partial^{2} \theta / \partial z^{2}$ has a maximum. The CBL grows downstream as sensible and latent heat are supplied from the sea surface.

When the upstream flow is vertically uniform and stratified uniformly, laboratory experiments (Brighton 1978; Boyer et al. 1987) showed that the necessary conditions for Kármán vortex shedding are $h<H$ and the classical Froude number $\mathrm{Fr} \equiv U / N H<0.4$, where 


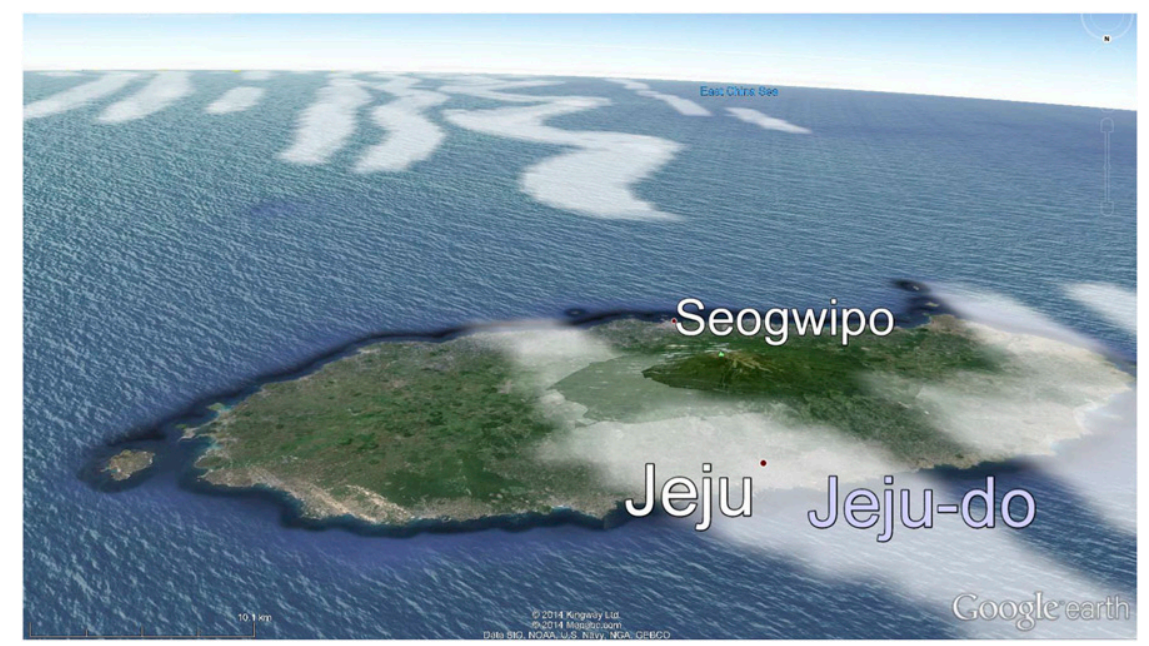

FIG. 4. Three-dimensional view of simulated cloud water mixing ratio overlaid on a Google Earth image by means of EXTRAWING (Araki et al. 2011) at 0000 UTC 16 Feb 2013. The viewpoint is located at the northwest of the island.

$N \equiv\left[\left(g / \theta_{0}\right) \partial \theta / \partial z\right]^{1 / 2}$ is the Brunt-Väisälä frequency, $g$ is the gravity coefficient, $\theta_{0}$ is the standard potential temperature, and $H$ is the height of an isolated threedimensional mountain (Etling 1989). If the upstream flow is associated with a CBL, however, other kinds of Froude numbers need to be considered (e.g., Etling 1989). Three kinds of them, $\mathrm{Fr}_{\text {div }}, \mathrm{Fr}_{s}$, and $\mathrm{Fr}_{B}$ are examined below.

One is a dividing streamline Froude number $\mathrm{Fr}_{\mathrm{div}} \equiv 1-h_{\mathrm{div}} / H$ (Snyder et al. 1985), where $h_{\text {div }}$ is the height of the dividing streamline. The wind encountering the mountain flows around the mountain below $h_{\text {div }}$ but overpasses above $h_{\text {div }}$. Following a procedure described in Heinze et al. (2012), we can obtain $h_{\text {div }}$ by implicitly solving the following equation:
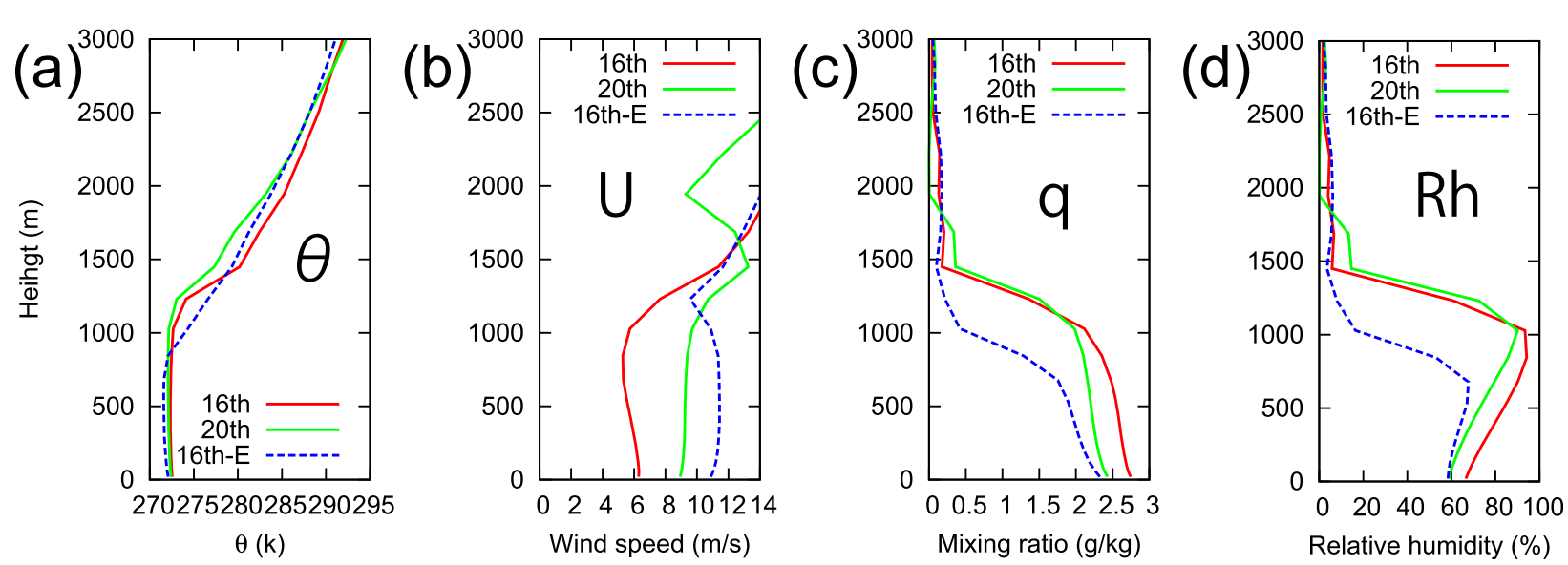

FIG. 5. Vertical profiles of (a) potential temperature, (b) wind speed, (c) water vapor mixing ratio, and (d) relative humidity just upstream of the Jeju Island (indicated by the white cross in Fig. 2a) at 0000 UTC 16 Feb (red solid line) and 20 Feb 2013 (green solid line). Profiles about $100 \mathrm{~km}$ east of the island (as indicated by a white circle in Fig. 2a) are also shown (blue dashed line). The data of $\theta$ and $U$ at the heights indicated by orange solid lines are used to obtain $\mathrm{Fr}_{s}$ and St.

Note that $\mathrm{Fr}_{\text {div }}$ depends only on the upstream vertical profiles of $U(z)$ and $\theta(z)$ above the CBL height in Figs. $5 \mathrm{a}$ and $5 \mathrm{~b}$. If the profiles in Fig. 5 at 0000 UTC 16 February are used, $h_{\text {div }}$ is calculated to be approximately $1300 \mathrm{~m}$ (see details in the appendix), and we obtain $\mathrm{Fr}_{\text {div }} \sim 0.13$.

The second one is a two-layer shallow-water Froude number $\mathrm{Fr}_{s}=U /\left(g h \Delta \theta / \theta_{0}\right)^{1 / 2}$ (Schär and Smith 1993), where $\Delta \theta$ is the potential temperature gap at the top of the CBL and $U$ is the averaged horizontal wind over the grid points in the CBL. Substituting $U \sim 6.0 \mathrm{~m} \mathrm{~s}^{-1}$ and 


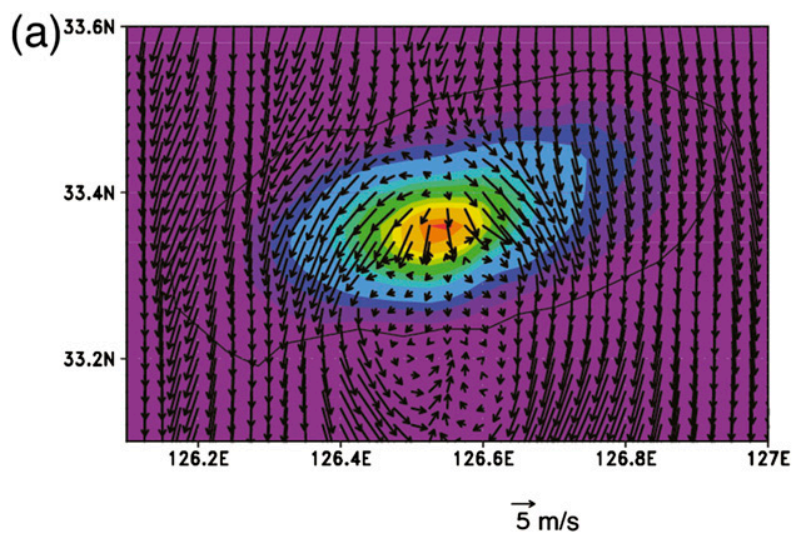

$1002003005006007009001000110013001400(\mathrm{~m})$

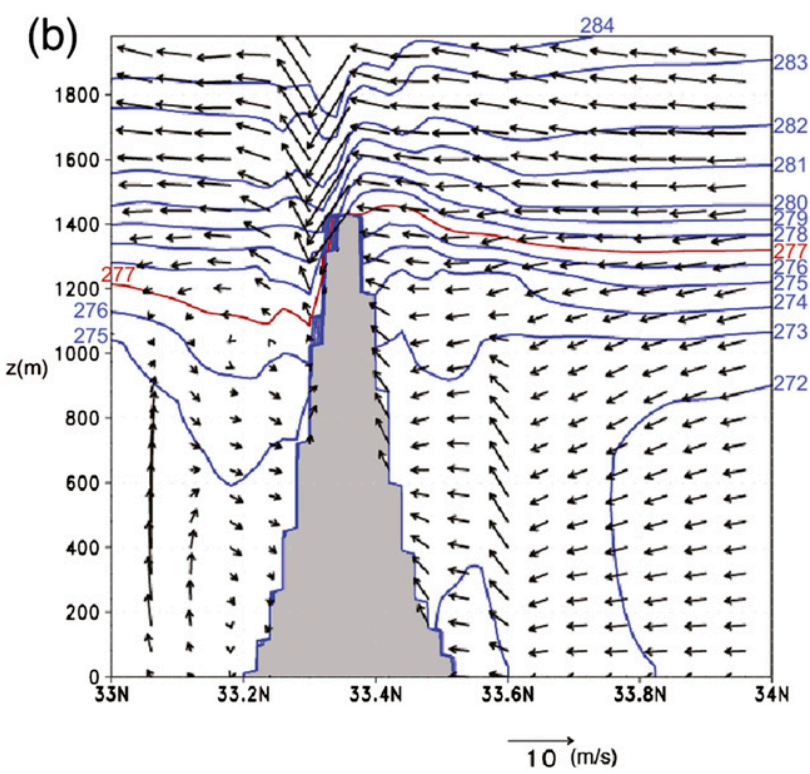

FIG. 6. (a) Horizontal wind vectors at the lowest grid level and topography height (shading) near the Jeju Island and (b) wind vectors and potential temperature (isolines of every $1 \mathrm{~K}$ ) in a latitudinal cross section at $126.5^{\circ} \mathrm{E}$ at $0000 \mathrm{UTC} 16 \mathrm{Feb} 2013$, where the scale of vertical velocity is expanded 20 times for the vectors in (b).

$\Delta \theta \sim 6.1 \mathrm{~K}$ at the top of the CBL whose height $h \sim 1200 \mathrm{~m}$ (Fig. 5a, see the appendix), and $\theta_{0} \sim 280 \mathrm{~K}$, $\mathrm{Fr}_{s}$ is estimated to be 0.37 at 0000 UTC 16 February. The LES results of Heinze et al. (2012) suggested that a clear vortex shedding occurs for $\mathrm{Fr}_{\text {div }}<0.36$ and $\mathrm{Fr}_{s}<0.80$, so that the present results are consistent with theirs.

Figure $6 \mathrm{a}$ indeed shows that the incoming flow below $h_{\text {div }} \sim 1300 \mathrm{~m}$ does not climb the mountain but flows around it. Figure $6 \mathrm{~b}$ depicts that the lowest isentrope that reaches the top of the mountain is $277 \mathrm{~K}$ : the isentropes lower than $277 \mathrm{~K}$ appear to go around the mountain, and those for 274 and $273 \mathrm{~K}$ do not appear in the south of the mountain in this vertical cross section. This flow pattern seems to be similar to that in wave breaking and flow splitting regime, which is found in the case of uniform stratification (Smith 1989) and is realized for roughly $\mathrm{Fr} \lesssim 1$ for Halla Mountain of Jeju Island whose spanwise axis is longer than streamwise axis [see Fig. 5 of Smith (1989)].

To consider the effects of nonuniform upwind stability, Reinecke and Durran (2008) also examined two kinds of the Froude numbers: a bulk Froude number $\mathrm{Fr}_{B}$ and an average Froude number $\mathrm{Fr}_{A}$. They found that the bulk Froude number,

$$
\operatorname{Fr}_{B}=\frac{U}{H \sqrt{\frac{g}{\theta_{0}} \frac{\theta(z=H)-\theta(z=0)}{H}}},
$$

is "a better predictor of the low-level flow diversion," where $\theta(z=H)$ and $\theta(z=0)$ are the potential temperature at the top of the mountain $H$ and at the ground, respectively. Substituting the averaged wind speed $U \sim 6.8 \mathrm{~m} \mathrm{~s}^{-1}$ between $z=0$ and $H, \theta(z=H)=280.7 \mathrm{~K}$, and $\theta(z=0) \sim$ $272.6 \mathrm{~K}$ at the lowest grid level (Fig. 5a), we obtain $\mathrm{Fr}_{B} \sim 0.33$, which indicates significant flow splitting for an isolated mountain of horizontal aspect ratio $\sim 2$ [see Fig. 14 in Reinecke and Durran (2008)].

The necessary conditions for vortex shedding are also satisfied at 0000 UTC 20 February, when $h_{\text {div }}$ is again estimated to be approximately $1300 \mathrm{~m}$ and $\mathrm{Fr}_{\text {div }} \sim 0.13$, and $\mathrm{Fr}_{s} \sim 0.71$, where $U=9.5 \mathrm{~m} \mathrm{~s}^{-1}$ is an averaged wind speed in the CBL, $\Delta \theta=4.2 \mathrm{~K}$, and $h \sim$ $1200 \mathrm{~m}$ are used as described in the appendix. Froude number $\mathrm{Fr}_{B}$ on this day results in 0.62 , which again suggests a significant flow splitting (Reinecke and Durran 2008). Rather curiously, Ágústsson and Ólafsson (2014) made a numerical simulation with finer resolution $(1 \mathrm{~km})$. Both of the Froude numbers $F_{\text {div }}$ and $\mathrm{Fr}_{s}$ in their environment are even smaller than our cases, but they did not reproduce clear vortices but a wavy wake [see Fig. 8 in Ágústsson and Ólafsson (2014)].

The geographic perspective suggests that the location of Jeju Island is favorable for Kármán vortex shedding, since the fetch from the continent to the island is large enough to develop a CBL over the Yellow Sea, but small enough to keep the height of the CBL less than the height of the mountain (Fig. 2b). An ample supply of water vapor from the sea surface (Fig. 2c) ensures that the top of the CBL is nearly saturated (Fig. 5d). 
Therefore, clouds can form easily if a small upward displacement is forced in the CBL. It is also possible that enhanced vertical momentum transfer in the CBL decelerates the wind to make Fr favorable to Kármán vortex shedding.

If Jeju Island were located on the west coast of the Korean Peninsula, Kármán vortex shedding could still occur, but would not be visible, since there is little moisture supply from the land surface of the Korean Peninsula, and the air in the wake is likely to be unsaturated (Fig. 5c). On the other hand, if Jeju Island were located south of its current position, $h$ would become larger than $H$ (Fig. 2b) so that the condition $h<H$ would not be satisfied.

\section{b. Structure of a vortex accompanying cloud}

In this subsection, we will focus on the structure of a particular vortex, which is indicated as vortex A in Fig. 7, at 0000 UTC 16 February. Vortex A is detached from the pair of large positive and negative relative vorticity regions adjacent to the lee side of Jeju Island. The region adjacent to the mountain has previously attracted research on the mechanism for vorticity generation and wake formation, especially at low Froude number. We do not pursue this point further here, but only note that the reversal of the lee wind implied in previous studies (e.g., Epifanio and Rotunno 2005) does occur in the lee of the island (Figs. 3a,e).

Figures $8 \mathrm{a}$ and $8 \mathrm{~b}$ show relative vertical vorticity, vertical velocity, and the cloud water mixing ratio through the center of vortex A. The vortex has relative vertical vorticity of the order of $10^{-4} \mathrm{~s}^{-1}$ (Fig. 8a), indicating that a Rossby number defined in terms of vertical vorticity has a value of about 5 . While the core of the vorticity with the maximum value of $\omega_{r} \sim 7 \times$ $10^{-4} \mathrm{~s}^{-1}$ is located near the top of the CBL, the region of positive vorticity extends downward to the surface. Hence, it may imprint on the sea surface as observed by $\mathrm{Li}$ et al. (2008), and also is expected to trigger an updraft just below the vortex due to convergence near the surface (i.e., Ekman pumping). Furthermore, the updraft accompanied by vortex $\mathrm{A}$ is $w_{m} \sim 0.4 \mathrm{~m} \mathrm{~s}^{-1}$ at the middle of the CBL and is stronger than that in cloud streets (e.g., $w_{m} \lesssim 0.2 \mathrm{~m} \mathrm{~s}^{-1}$ in those at $126.05^{\circ}$ and $126.2^{\circ} \mathrm{E}$ in Fig. 8b).

The updraft is accelerated by the buoyancy force $F_{b}$ that is estimated to $\Delta \theta^{\prime} \times g / \theta_{0} \sim 0.5 \times 9.8 / 280 \sim$ $1.8 \times 10^{-2} \mathrm{~N}$, where $\Delta \theta^{\prime} \sim 0.5 \mathrm{~K}$ is a typical positive perturbation of $\theta$ in the CBL (Fig. 8c). In addition to the buoyancy, the nonhydrostatic vertical pressure gradient force also accelerates the updraft in the vortex core near the top of the CBL. Assuming a Rankine-type vortex, one may roughly estimate pressure depression

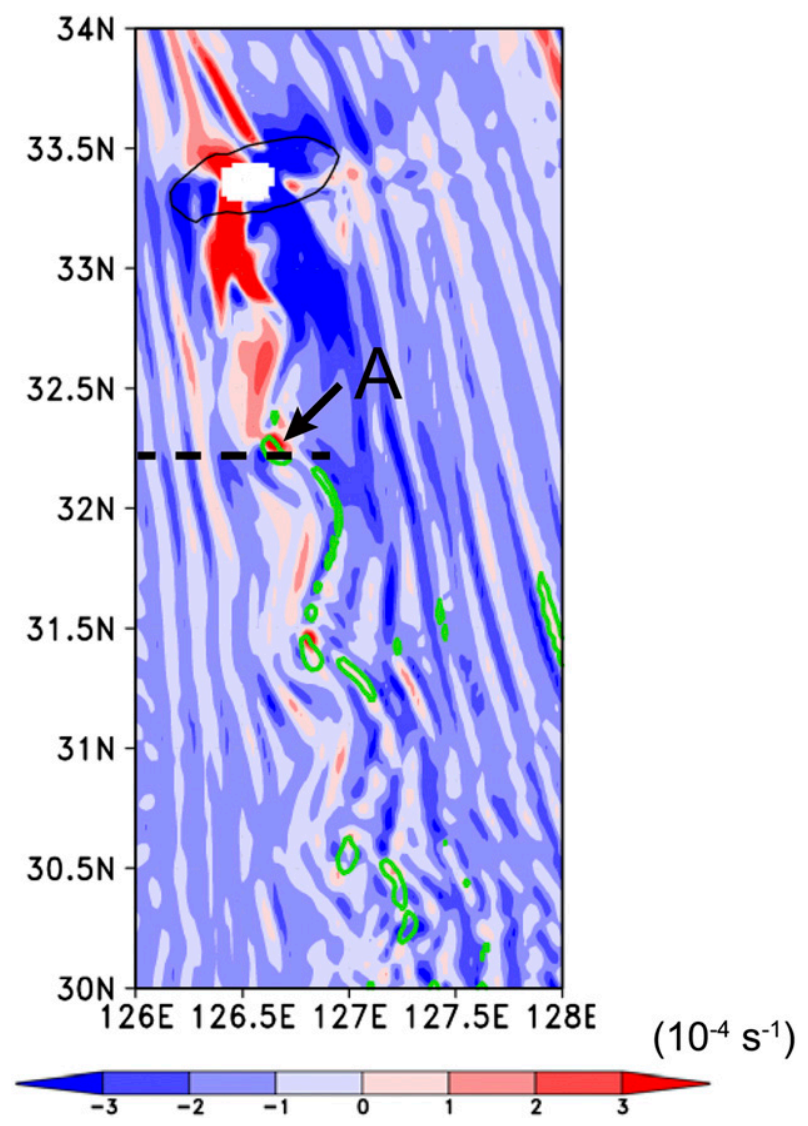

FIG. 7. Relative vorticity at $z=1028 \mathrm{~m}$ (red and blue shading) and cloud water amount in the vertical column for values above $40 \mathrm{~g} \mathrm{~kg}^{-1} \mathrm{~m}^{-2}$ (green contour) at 0000 UTC 16 Feb 2013.

at the core of vortex $\mathrm{A}$ in Fig. 8 by $\Delta p \sim-\rho \omega_{r}^{2} r^{2} \sim$ $-\left(6 \times 10^{-4}\right)^{2} \times\left(4 \times 10^{3}\right)^{2} \sim-5.8 \mathrm{~Pa}$, where $\rho$ is the density of the air, and $r$ is radius of the vortex core in the rigid-body rotation. The nonhydrostatic pressure gradient force $F_{p z} \equiv-d p / d z$ associated with the vortex at the capping of CBL is then estimated as $F_{p z} \sim-\Delta p / 1000 \mathrm{~m} \sim 5.8 \times 10^{-3} \mathrm{~N}$. Thus, the upward pressure gradient force $F_{p z}$, which is about one-third of $F_{b}$, would preferentially intensify updrafts associated with vortices. Moist air associated with enhanced updraft near the center of the vortices penetrates above the top of the CBL and results in the formation of small cumulus clouds that make the vortices visible on satellite images.

When the region is covered by stratocumulus as in several previous studies (e.g., Ágústsson and Ólafsson 2014), the vortices are characterized by cloud-free region that is associated with warm cores of vortices (Heinze et al. 2012). In the present case, vortex A is also accompanied by a warm core (Fig. 8c).

At the middle height of the CBL (Fig. 9), the latitudinal gradient of temperature is more significant than the temperature deviation associated with the 

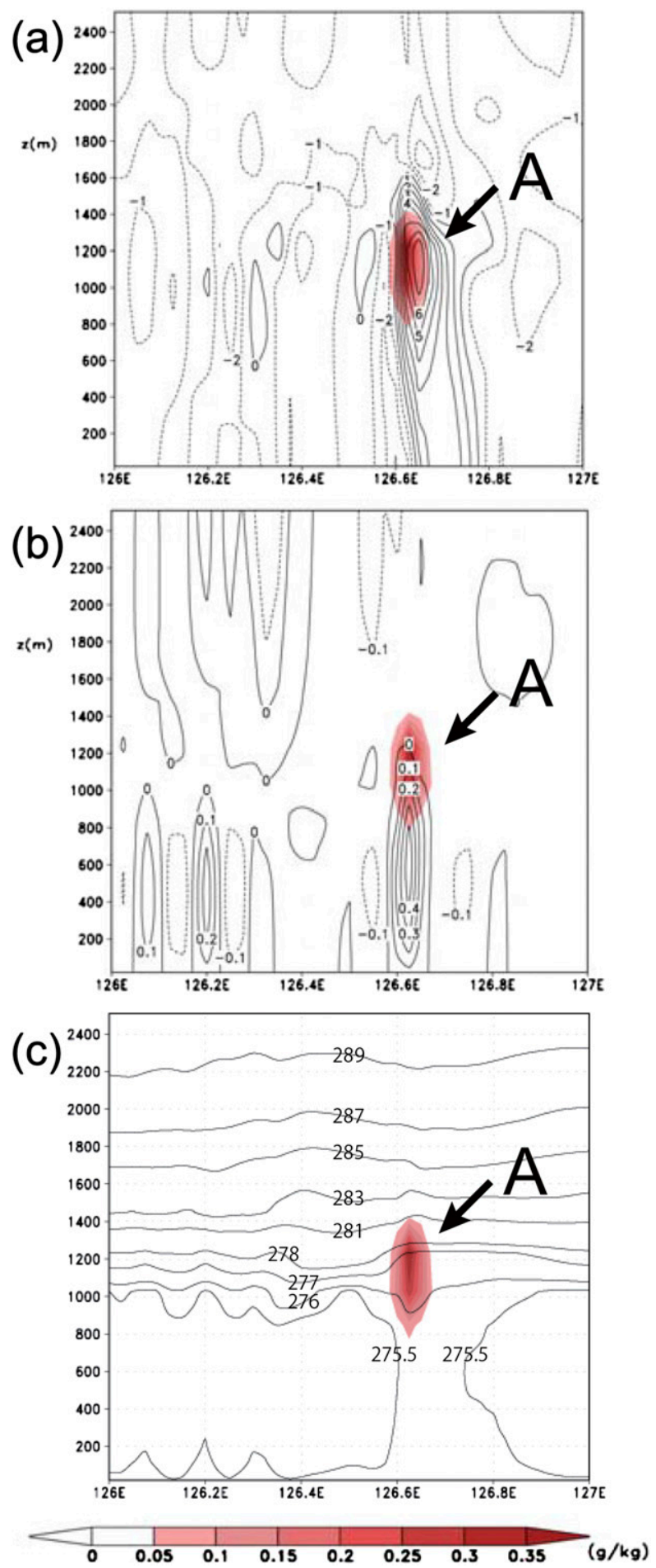

FIG. 8. (a) Vertical cross section of relative vorticity (contours; $10^{-4} \mathrm{~s}^{-1}$ ) and cloud water mixing ratio (red shading) through vortex A along the dotted line in Fig. 7. (b) As in (a), but the contour lines represent vertical velocity $\left(\mathrm{m} \mathrm{s}^{-1}\right)$. (c) As in (a), but the contour lines represent potential temperature $(\mathrm{K})$.

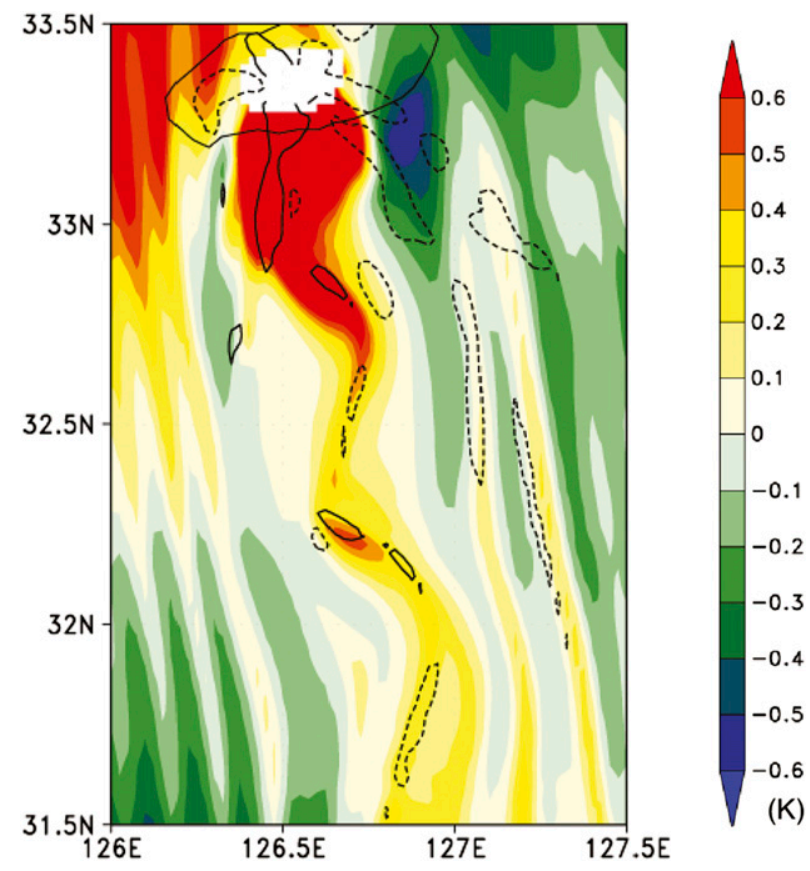

FIG. 9. Potential temperature deviation from longitudinal average at $z=530 \mathrm{~m}$ (shading) and relative vorticity larger than $10^{-4} \mathrm{~s}^{-1}$ (solid lines) and smaller than $-10^{-4} \mathrm{~s}^{-1}$ (dashed lines) at $z=1028 \mathrm{~m}$ (black contour) at 0000 UTC 16 Feb 2013.

vortices unlike the idealized LES (Heinze et al. 2012). Nevertheless, the vortex street is characterized by a positive anomaly of potential temperature at each latitude.

The relative vorticity of these vortices is of the order of $10^{-4} \mathrm{~s}^{-1}$, an order of magnitude smaller than that of mesoscale vortices formed in the Japan Sea polarairmass convergence zone (e.g., Watanabe and Niino 2014). The latter vortices are accompanied by heavy snowfall along the coast of the Sea of Japan, while the Kármán vortices are associated with a small amount of cloud water that has little impact on the weather. Satellite images show cloud-free eyes in the cores of vortices at the almost finest resolved scale of the images (Fig. 1a). Simulated vortices do not show such a structure; further improvement in the horizontal resolution seems to be required.

\section{c. Vorticity formation mechanism}

We also performed a sensitivity experiment to examine the origin of the vortices. As mentioned in the introduction, several previous numerical studies have suggested that Kármán vortex shedding occurs even when a free-slip boundary condition is imposed on the topography. To examine the vorticity source for the vortices, surface drag over Jeju Island, which occupies 472 grid points, is turned off. 
The Kármán vortex shedding in the sensitivity experiment turns out to be almost indistinguishable from the standard experiment (not shown). This result demonstrates that the vorticity of the Kármán vortices does not have its origin in the "viscous" boundary layer.

Both baroclinicity caused by the flow over the mountain and gravity wave breaking would form lee vortices in the absence of the viscous boundary layer. We do not make further detailed analysis such as a vorticity budget, but we would like to point out that gravity wave breaking seems to be evident in a potential temperature profile in a vertical-streamwise section of the flow over the mountain: the stratified layer above the CBL is significantly distorted to the lee of Jeju Island (Fig. 6b).

\section{Conclusions}

A mesoscale nonhydrostatic numerical model, which is used for daily numerical weather prediction, is shown to successfully reproduce the atmospheric Kármán vortex shedding associated with characteristic cloud pattern in the lee of Jeju Island on 16 and 20 February 2013.

Based on the numerical results, we have discussed the environment and dynamics of atmospheric Kármán vortex shedding. The winter monsoon over the Yellow Sea is associated with a CBL that grows downstream, but the CBL height remains smaller than the mountain height when it reaches Jeju Island. This makes Jeju Island a favorable location for the generation of Kármán vortices. A sensitivity experiment in which the island surface is set to be free-slip implies that the vortices do not originate from the "viscous" boundary layers.

This study demonstrates that an operational weather prediction model with moderate horizontal resolution can be used to reproduce and study local meteorological phenomena such as Kármán vortex shedding. While we have succeeded in reproducing Kármán vortex shedding, the longitudinal cloud streets (Figs. 3a,e and 4) are not as numerous as observed on the satellite images (Fig. 1). A further improvement in the horizontal resolution may lead to a better reproduction of such smallscale features (e.g., Eito et al. 2004), although turbulence parameterizations need to be carefully modified when the horizontal resolution becomes $1 \mathrm{~km}$ or less (e.g., Honnert et al. 2011).

Acknowledgments. This work was supported by Field 3, Strategic Programs for Innovative Research, Ministry of Education, Culture, Sports, Science and Technology of the Japanese government. We thank the editor, Dr. Daniel Kirshbaum, and two anonymous reviewers for their helpful comments.

\section{APPENDIX}

\section{Procedure to Estimate Froude Numbers}

We have used the simulation results of $U\left(z_{j}\right), \theta\left(z_{j}\right)$ to estimate various quantities at the upstream point $\left(33.7^{\circ} \mathrm{N}, 126.4^{\circ} \mathrm{E}\right)$, which is indicated by the white plus mark in Fig. 2a, where $z_{j}$ denotes each grid level. Brunt-Väisälä frequency $N\left(z_{j}\right)$ is evaluated only at the stably stratified levels for which $\theta\left(z_{j+1}\right)-\theta\left(z_{j-1}\right)>0$. For estimating $\mathrm{Fr}_{\mathrm{div}}$, we consider a function of $z$, $F(z) \equiv(1 / 2) U^{2}(z)-\int_{z}^{H} N^{2}\left(z^{\prime}\right)\left(H-z^{\prime}\right) d z^{\prime}$, where the integral is approximated by the trapezoidal rule. When $z$ is decreased from $H=1500 \mathrm{~m}, F(z)$ changes it sign between $z_{j+1}$ and $z_{j}$. Then $h_{\mathrm{div}}$ is estimated as $\left[F\left(z_{j+1}\right) z_{j}-\right.$ $\left.F\left(z_{j}\right) z_{j+1}\right]\left[F\left(z_{j+1}\right)-F\left(z_{j}\right)\right]$.

For estimating $\mathrm{Fr}_{s}$, the height of CBL $h$ above which the strongest stratification of $\theta\left(z_{j}\right)$ exists is estimated to be $1230 \mathrm{~m}$ on both days, where the temperature gaps $\Delta \theta \equiv \theta\left(z_{j}=1450 \mathrm{~m}\right)-\theta\left(z_{j}=1230 \mathrm{~m}\right)$ are 6.1 and $4.2 \mathrm{~K}$ on 16 and 20 February, respectively.

\section{REFERENCES}

Ágústsson, H., and H. Ólafsson, 2014: The advection of mesoscale atmospheric vortices over Reykjavík. Mon. Wea. Rev., 142 , 3549-3559, doi:10.1175/MWR-D-13-00060.1.

Araki, F., S. Kawahara, D. Matsuoka, T. Sugimura, Y. Baba, and K. Takahashi, 2011: Studies of large-scale data visualization: EXTRAWING and visual data mining. Annual Report of the Earth Simulator Center April, Earth Simulator Center, Japan Agency for Marine-Earth Science and Technology, 195-199. [Available online at https://www.jamstec.go. jp/esc/publication/annual/annual2010/pdf/2project/chapter3/ 195araki.pdf.]

Asai, T., 1970: Stability of a plane parallel flow with variable vertical shear and unstable stratification. J. Meteor. Soc. Japan, 48, 129-139.

Beljaars, A., and A. Holtslag, 1991: Flux parameterization over land surfaces for atmospheric models. J. Appl. Meteor., 30, 327-341, doi:10.1175/1520-0450(1991)030<0327:FPOLSF > 2.0.CO;2.

Boyer, D., P. Davies, W. Holland, F. Biolley, and H. Honji, 1987: Stratified rotating flow over and around isolated threedimensional topography. Philos. Trans. Roy. Soc. London, A322, 213-241, doi:10.1098/rsta.1987.0049.

Brighton, P., 1978: Strongly stratified flow past three-dimensional obstacles. Quart. J. Roy. Meteor. Soc., 104, 289-307, doi:10.1002/qj.49710444005.

Caldeira, R. M. A., and R. Tomé, 2013: Wake response to an oceanfeedback mechanism: Madeira Island case study. Bound.Layer Meteor., 148, 419-436, doi:10.1007/s10546-013-9817-y.

Chung, Y. S., and H. S. Kim, 2008: Mountain-generated vortex streets over the Korea South Sea. Int. J. Remote Sens., 29, 867877, doi:10.1080/01431160701281080.

Couvelard, X., R. M. A. Caldeira, I. B. Araújo, and R. Tomé, 2012: Wind mediated vorticity-generation and eddyconfinement, leeward of the Madeira Island: 2008 numerical case study. Dyn. Atmos. Oceans, 58, 128-149, doi:10.1016/ j.dynatmoce.2012.09.005. 
Eito, H., C. Muroi, S. Hayashi, T. Kato, and M. Yoshizaki, 2004: A high-resolution wide-range numerical simulation of cloud bands associated with the Japan Sea Polar-air mass Convergence Zone in winter using a non-hydrostatic model on the Earth Simulator. CAS/JSC WGNE Res. Act. Atmos. Ocean Model, 34, 5.07-5.08. [Available online at http://www. wcrp-climate.org/WGNE/BlueBook/2004/individual-articles/ 05_Eito_Hisaki_05_eito_hisaki_JPCZ2001.pdf.]

Epifanio, C., and R. Rotunno, 2005: The dynamics of orographic wake formation in flows with upstream blocking. J. Atmos. Sci., 62, 3127-3150, doi:10.1175/JAS3523.1.

Etling, D., 1989: On atmospheric vortex streets in the wake of large islands. Meteor. Atmos. Phys., 41, 157-164, doi:10.1007/ BF01043134.

Gryschka, M., J. Fricke, and S. Raasch, 2014: On the impact of forced roll convection on vertical turbulent transport in cold air outbreaks. J. Geophys. Res. Atmos., 119, 12 513-12532, doi:10.1002/2014JD022160.

Heinze, R., S. Raasch, and D. Etling, 2012: The structure of Kármán vortex streets in the atmospheric boundary layer derived from large eddy simulation. Meteor. Z., 21, 221-237, doi:10.1127/0941-2948/2012/0313.

Hirahara, Y., J. Ishida, and T. Ishimizu, 2011: Trial operation of the Local Forecast Model at JMA. CAS/JSC WGNE Res. Act. Atmos. Ocean Model, 41, 5.11-5.12. [Available online at http:// www.wcrp-climate.org/WGNE/BlueBook/2011/individualarticles/05_Hirahara_Youichi_WGNE_LFM.pdf.]

Honnert, R., V. Masson, and F. Couvreux, 2011: A diagnostic for evaluating the representation of turbulence in atmospheric models at the kilometric scale. J. Atmos. Sci., 68, 3112-3131, doi:10.1175/JAS-D-11-061.1.

Jensen, N. O., and E. M. Agee, 1978: Vortex cloud street during AMTEX 75. Tellus, 30A, 517-523, doi:10.1111/ j.2153-3490.1978.tb00868.x.

Kang, S.-D., F. Kimura, and S. Takahashi, 1998: A numerical study on the Kármán vortex generated by divergence of momentum flux in flow past an isolated mountain. J. Meteor. Soc. Japan, 76, 925-935.

Li, X., W. Zheng, C.-Z. Zou, and W. G. Pichel, 2008: A SAR observation and numerical study on ocean surface imprints of atmospheric vortex streets. Sensors, 8, 3321-3334, doi:10.3390/ s8053321.

Lin, Y.-L., R. D. Farley, and H. D. Orville, 1983: Bulk parameterization of the snow field in a cloud model. J. Climate Appl. Meteor., 22, 1065-1092, doi:10.1175/1520-0450(1983)022<1065: BPOTSF $>2.0 . \mathrm{CO} ; 2$.

Mallock, A., 1907: On the resistance of air. Proc. Roy. Soc. London, 79, 262-273, doi:10.1098/rspa.1907.0038.

Muller, B. M., C. G. Herbster, and F. R. Mosher, 2015: An unusual aerial photograph of an eddy circulation in marine stratocumulus clouds. Mon. Wea. Rev., 143, 419-432, doi:10.1175/ MWR-D-13-00316.1.

Nakanishi, M., and H. Niino, 2006: An improved Mellor-Yamada level-3 model: Its numerical stability and application to a regional prediction of advection fog. Bound.-Layer Meteor., 119, 397-407, doi:10.1007/s10546-005-9030-8.

Nunalee, C. G., and S. Basu, 2014: On the periodicity of atmospheric von Kármán vortex streets. Environ. Fluid Mech., 14, 1335-1355, doi:10.1007/s10652-014-9340-9.

Reinecke, P. A., and D. R. Durran, 2008: Estimating topographic blocking using a Froude number when the static stability is nonuniform. J. Atmos. Sci., 65, 1035-1048, doi:10.1175/ 2007JAS2100.1.

Rotunno, R., and P. K. Smolarkiewicz, 1991: Further results on lee vortices in low-Froude-number flow. J. Atmos. Sci., 48, 2204-2211, doi:10.1175/1520-0469(1991)048<2204: FROLVI $>2.0 . \mathrm{CO} ; 2$.

Ruscher, P. H., and J. W. Deardorff, 1982: A numerical simulation of an atmospheric vortex street. Tellus, 34A, 555-566, doi:10.1111/j.2153-3490.1982.tb01844.x.

Saito, K., and Coauthors, 2006: The operational JMA nonhydrostatic mesoscale model. Mon. Wea. Rev., 134, 1266-1298, doi:10.1175/MWR3120.1.

Schär, C., and R. B. Smith, 1993: Shallow-water flow past isolated topography. Part I: Vorticity production and wake formation. J. Atmos. Sci., 50, 1373-1400, doi:10.1175/ 1520-0469(1993)050<1373:SWFPIT >2.0.CO;2.

, and D. R. Durran, 1997: Vortex formation and vortex shedding in continuously stratified flows past isolated topography. J. Atmos. Sci., 54, 534-554, doi:10.1175/ 1520-0469(1997)054<0534:VFAVSI >2.0.CO;2.

Smith, R. B., 1989: Hydrostatic airflow over mountains. Advances in Geophysics, Vol. 31, Academic Press, 1-41, doi:10.1016/ S0065-2687(08)60052-7.

Smolarkiewicz, P. K., and R. Rotunno, 1989: Low Froude number flow past three-dimensional obstacles. Part I: Baroclinically generated lee vortices. J. Atmos. Sci., 46, 1154-1164, doi:10.1175/1520-0469(1989)046<1154:LFNFPT>2.0.CO;2.

Snyder, W. H., R. S. Thompson, R. E. Eskridge, R. E. Lawson, I. P. Castro, J. Lee, J. C. Hunt, and Y. Ogawa, 1985: The structure of strongly stratified flow over hills: Dividing-streamline concept. J. Fluid Mech., 152, 249-288, doi:10.1017/ S0022112085000684.

Thomson, R. E., J. F. R. Gower, and N. W. Bowker, 1977: Vortex streets in the wake of the Aleutian Islands. Mon. Wea. Rev., 105, 873-884, doi:10.1175/1520-0493(1977)105<0873: VSITWO $>2.0 . \mathrm{CO} ; 2$.

Tsuchiya, K., 1969: The clouds with the shape of Kármán vortex street in the wake of Cheju Island, Korea. J. Meteor. Soc. Japan, 47, 457-465.

von Kármán, T., and H. Rubach, 1912: Über den Mechanismus des Flüssigkeits-und Luftwiderstandes (On the mechanism of the resistance in fluids). Phys. Z., 13, 49-59.

Watanabe, S. I., and H. Niino, 2014: Genesis and development mechanisms of a polar mesocyclone over the Japan Sea. Mon. Wea. Rev., 142, 2248-2270, doi:10.1175/MWR-D-13-00226.1.

Young, G. S., and J. Zawislak, 2006: An observational study of vortex spacing in island wake vortex streets. Mon. Wea. Rev., 134, 2285-2294, doi:10.1175/MWR3186.1. 